\title{
NDM-1 producing Acinetobacter baumannii isolated from a patient repatriated to the Czech Republic from Egypt, July 2011
}

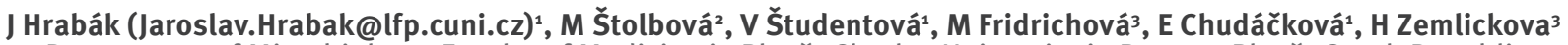

1. Department of Microbiology, Faculty of Medicine in Plzeň, Charles University in Prague, Plzeň, Czech Republic

2. Department of Clinical Microbiology, Masaryk`s Hospital, Ústí nad Labem, Czech Republic

3. National Reference Laboratory for Antibiotics, National Institute of Health, Prague, Czech Republic

Hrabák J, Stolbová M, Študentová V, Fridrichová M, Chudáčková E, Zemlickova H. NDM-1 producing Acinetobacter baumannii isolated from a patient repatriated to the Czech Republic from Egypt, July 2011.

Euro Surveill. 2012;17(7):pii=20085. Available online: http://www.eurosurveillance.org/ViewArticle.aspx?Articleld=20085

Article published on 16 February 2012

We describe the isolation of an NDM-1-producing Acinetobacter baumannii in a Czech patient repatriated in July 2011 from Egypt. The infection spread to another patient on the same ward. Both isolates showed the same resistance pattern and were susceptible only to colistin. They had an identical PFGE pattern and belonged to the same sequence type ST 1. Sequencing of the $b a_{N D M}$ gene identified the NDM-1 variant of the carbapenemase, surrounded by two copies of insertion sequence ISAba125.

Here we describe the isolation of a New Delhi metallobeta-lactamase-1 (NDM-1)-producing Acinetobacter baumannii in a Czech citizen repatriated from Egypt in July 2011. The patient was hospitalised in Egypt, and then transferred to a hospital in the Czech Republic. The patient developed ventilator-associated pneumonia caused by $A$. baumannii in addition to a primary neurological diagnosis. A carbapenem-resistant A. baumannii strain ( $\left.\mathrm{V}_{509}\right)$ was isolated from bronchoalveolar lavage and an oral cavity swab. He was initially treated by meropenem and metronidazole. Due to progression of the primary disease, the patient was transferred to a long-term intensive care unit. Although the antibiotic regimen was not changed, the patient recovered according to the biochemical markers of inflammation within seven days and the antibiotic therapy was then stopped. The available data are not conclusive as to whether this patient was infected or colonised. However, the resistant isolate has been detected in low quantity in oral swab and bronchoalveolar lavage until the transfer to the long-term intensive care unit. The intensive care centre was informed about the epidemiological risk associated with this patient so that they could prepare for appropriate measures upon transfer.

A second $A$. baumannii isolate $\left(V_{566}\right)$ with the same resistance pattern was recovered six days later from the airways of another ventilated patient sharing the same room. The patient was treated with amoxicillin/ clavulanic acid, chloramphenicol and ciprofloxacin. He died due to respiratory failure four days after the first isolation of NDM-1-producing A. baumannii.

\section{Laboratory analysis}

The isolates from both patients were identified as $A$. baumannii by biochemical test API ID32 GN (bioMérieux, France) and by matrix-assisted laser desorption/ionisation time-of-flight (MALDI-TOF) mass spectrometry (Bruker Daltonics, Germany). The minimum inhibitory concentrations (MICs) to 14 antibiotics were tested and the results were interpreted according to the EUCAST recommendation [1]. The isolates from both patients were resistant to all beta-lactams tested including carbapenems and other antibiotics (Table).

Typing performed by pulsed-field gel electrophoresis (PFGE) [2] showed that the isolates had indistinguishable macrorestriction patterns. Carbapenemase production was confirmed by MALDI-TOF mass spectrometry [3]. Production of metallo-beta-lactamase (MBL) activity was verified by ethylenediaminetetraacetic acid (EDTA) double-disk synergy test [4].

The bla $a_{\text {NDM }}$ gene of both isolates was amplified and sequenced as described previously [5], and revealed the NDM-1 variant of the enzyme. The bla $a_{\mathrm{NDM}-1}$ together with other genes was located between two copies of the insertion sequence ISAba125 in the same orientation as found by Pfeifer et al. [6]. Because plasmid preparations from the two isolates did not yield any plasmids visible after electrophoretic separation, and no transformants were obtained after transformation experiments performed as previously described [7], it can be hypothesised that bla $a_{\mathrm{NDM}-1}$ is located on the bacterial chromosome. 
Multi-locus sequence typing (MLST) was performed [8] and the MLST database available at the website of the Pasteur Institute was used to assign the sequence type (ST). Both isolates belonged to sequence type (ST) 1 (allelic profile 1-1-1-1-5-1-1) which represents the epidemiologically successful European clone I [9].

\section{Discussion and conclusion}

Reports describing NDM-type carbapenemase producers isolated from patients previously hospitalised in high-prevalence countries have been increasing. Pfeifer et al. detected NDM-1 in A. baumannii isolated from a patient repatriated to Germany from Serbia in 2007 [6]. Importation of NDM-1-producing A. baumannii strain from Serbia has also been described by Poirel et al. [10]. Other $A$. baumannii isolates expressing NDM-1 MBL have been isolated in China and India $[11,12]$. It is remarkable that $b a_{\mathrm{NDM}-1}$ was also found on a plasmid in A. Iwoffii in China [13]. The new NDM-2 variant was first detected in $A$. baumannii from a patient transferred from Egypt to Germany [5]. Recently, clonal spread of NDM-2-producing A. baumannii strains have been described in a rehabilitation ward in Israel and in the United Arab Emirates [14,15].

Until this report, no NDM-1 producing bacterium had been described in the Czech Republic, a country with a low prevalence of carbapenemase-producing bacteria [16-18]. Although routine procedures were in place in the hospital department, the strain quickly spread within one ward to another patient. After the death of the second patient and the transfer of the first patient to the long-term intensive care unit centre, the department was closed for two weeks and general cleaning including decontamination of all equipment was undertaken. No NDM-1-producing strain has been detected

\section{TABLE}

Antimicrobial susceptibility of the NDM-1-producing Acinetobacter baumannii isolates, Czech Republic, July $2011(\mathrm{n}=2)$

\begin{tabular}{|l|c|}
\hline Antibiotic & MIC $[\mu \mathrm{g} / \mathrm{ml}]$ \\
\hline Ampicillin-sulbactam & 32 \\
\hline Piperacillin & $>64$ \\
\hline Piperacilin-tazobactam & $>64$ \\
\hline Ceftazidime & $>32$ \\
\hline Cefepime & $>32$ \\
\hline Meropenem & $>32$ \\
\hline Ciprofloxacin & $>32$ \\
\hline Nalidixic acid & $>64$ \\
\hline Gentamicin & 32 \\
\hline Amikacin & 32 \\
\hline Tetracycline & 64 \\
\hline Chloramphenicol & 8 \\
\hline Colistine & $<0.5$ \\
\hline Trimethoprim-sulfamethoxazole & 16 \\
\hline
\end{tabular}

MIC: minimum inhibitory concentrations; NDM-1: New Delhi metallo-beta-lactamase-1. after the cleaning. Due to the importance of international travel in the spread of bacterial resistance, fast detection and active surveillance of bacteria producing acquired carbapenemases is needed $[5-7,10,16,18,19]$.

We also tested the new MALDI-TOF mass spectrometry approach [3] for the detection of carbapenemase activity in the isolates. Although phenotypical detection of carbapenem-hydrolyzing enzymes in $A$. baumannii seems to be difficult by conventional methods [20], we were able to see a clear carbapenemase activity by this assay. Further validation, however, is necessary.

\section{Acknowledgments}

This work was supported by the research project grants NT11032-6/2010 and NS9717-4/2008 from the Ministry of Health of the Czech Republic and MSMo021620819 from the Ministry of Education of the Czech Republic.

\section{References}

1. European Committee for Antimicrobial Susceptibility Testing (EUCAST). Determination of minimum inhibitory concentrations (MICS) of antibacterial agents by broth dilution. EUCAST discussion document E.Dis. 5.1. March 2003. Clin Microbiol Infect. 2003;9(8):1-7. Available from: http://onlinelibrary.wiley. com/doi/10.1046/j.1469-0691.2003.00790.x/pdf

2. Struelens MJ, Rost F, Deplano A, Maas A, Schwarm V, Serruys $E$, et al. Pseudomonas aeruginosa and Enterobacteriaceae bacteremia after biliary endoscopy: an outbreak investigation using DNA macrorestriction analysis. Am J Med. 1993;95(5):489-98.

3. Hrabák J, Walková R, Študentová V, Chudáčková E, Bergerová Y. Carbapenemase Activity Detection by Matrix-Assisted Laser Desorption/Ionisation Time-of-Flight (MALDI-TOF) Mass Spectrometry. J Clin Microbiol. 2011;49(9):3222-7.

4. Miriagou V, Cornaglia G, Edelstein M, Galani I, Giske CG, Gniadkowski M, et al. Acquired carbapenemases in Gramnegative bacterial pathogens: detection and surveillance issues. Clin Microbiol Infect. 2010;16(2):112-22.

5. Kaase M, Nordmann P, Wichelhaus TA, Gatermann SG, Bonnin RA, Poirel L. NDM-2 carbapenemase in Acinetobacter baumannii from Egypt. J Antimicrob Chemother. 2011;66(6):1260-2

6. Pfeifer Y, Wilharm G, Zander E, Wichelhaus TA, Götting S, Hunfeld KP, et al. Molecular characterization of blaNDM-1 in an Acinetobacter baumannii strain isolated in Germany in 2007. J Antimicrob Chemother. 2011;66(9):1998-2001.

7. Hrabák J, Niemczyková J, Chudáčková E, Fridrichová M, Studentová V, Červená D, et al. KPC-2-producing Klebsiella pneumoniae isolated from a Czech patient previously hospitalized in Greece and in vivo selection of colistin resistance. Folia Microbiol. 2011;56(4):361-5.

8. Acinetobacter baumannii. MLST Database. Paris: Institut Pasteur. [Accessed: 19 Sep 2011]. Available from: www.pasteur. $\mathrm{fr} /$ recherche/genopole/PF8/mlst/Abaumannii.html

9. Dijkshoorn L, Nemec A, Seifert H. An increasing threat in hospitals: multidrug-resistant Acinetobacter baumannii. Nat Rev Microbiol. 2007;5(12):939-51.

10. Poirel L, Bonnin RA, Boulanger A, Schrenzel J, Kaase M, Nordmann P. Tn125-Related Acquisition of blaNDM-Like Genes in Acinetobacter baumannii. Antimicrob Agents Chemother. 2011;56(2):1087-9.

11. Chen $Y$, Zhou Z, Jiang Y, Yu Y. Emergence of NDM-1-producing Acinetobacter baumannii in China. J Antimicrob Chemother. 2011;66(6):1255-9.

12. Karthikeyan K, Thirunarayan MA, Krishnan P. Coexistence of blaOXA-23, with blaNDM-1 and armA in clinical isolates of Acinetobacter baumannii from India. J Antimicrob Chemother. 2010;65(10):2253-4.

13. Hu Y, Zhang W, Liang H, Liu L, Peng G, Peng G, et al. Wholegenome sequence of a multidrug resistant clinical isolate of Acinetobacter Iwoffii. J Bacteriol. 2011;193(19):5549-50.

14. Espinal P, Fugazza G, López Y, Kasma M, Lerman Y, MalhotraKumar S, et al. Dissemination of the NDM-2-producing 
Acinetobacter baumannii clone in an Israeli Rehabilitation

Center. Antimicrob Agents Chemother. 22011;55(11):5396-8.

15. Ghazawi A, Sonnevend A, Bonnin RA, Poirel L, Nordmann

P, Hashmey R, et al. NDM-2 carbapenemase-producing

Acinetobacter baumannii in the United Arab Emirates. Clin

Microbiol Infect. 2012;18(2):E34-6.

16. Grundmann H, Livermore DM, Giske CG, Cantón R, Rossolini GM, Campos J, et al. Carbapenem-non-susceptible

Enterobacteriaceae in Europe: conclusions from a meeting of national experts. Euro Surveill. 2010;15(46):pii=19711. Available from: http://www.eurosurveillance.org/ViewArticle. aspx?Articleld=19711

17. Hrabák J, Červená D, Izdebski R, Duljasz W, Gniadkowski $M$, Fridrichová $M$, et al. Regional spread of Pseudomonas aeruginosa ST357 producing the IMP-7 metallo- $\beta$-lactamase in the Central Europe. J Clin Microb. 2011;49(1):474-5.

18. Struelens MJ, Monnet DL, Magiorakos AP, Santos O'Connor F, Giesecke J, et al. New Delhi metallo-beta-lactamase-producing Enterobacteriaceae: emergence and response in Europe. Euro Surveill. 2010;15(46):pii=19716. Available from: http://www. eurosurveillance.org/ViewArticle.aspx?Articleld=19716

19. Hrabák J, Empel J, Gniadkowski M, Halbhuber Z, Rébl K, Urbášková P. CTX-M-15-producing Shigella sonnei from a Czech patient who traveled in Asia. J Clin Microbiol. 2008;46(6):2147-8.

20. Bonnin RA, Naas T, Poirel L, Nordmann P. Phenotypical-, biochemical- and molecular-based techniques for detection of metallo- $\beta$-lactamase NDM in Acinetobacter baumannii. J Clin Microbiol. 2012 Jan 18. [Epub ahead of print] 